\title{
ALGUNAS CONSIDERACIONES SOBRE LA REDEFINICIÓN DEL CAMPO DE LA ANTROPOLOGÍA RURAL
}

Some considerations on the redefinition of the field of Rural anthropology

\section{ALEJANDRO BALAZOTE* Y SEBASTIÁN VALVERDE**}

\author{
Fecha de recepción: 27 de diciembre de 2016 - Fecha de aprobación: 30 de marzo de 2017
}

\section{Resumen}

En este trabajo analizamos la redefinición del campo de la Antropología Rural acaecida en los últimos años, a partir de la configuración de un escenario socioeconómico y cultural caracterizado por la emergencia de nuevos actores económicos, por la implementación de disímiles modalidades de explotación del trabajo rural, por la yuxtaposición de formatos productivos y estrategias de comercialización, por la incidencia de la estructura financiera nacional e internacional y fundamentalmente por la puesta en marcha de un novedoso sistema de apropiación de la renta agropecuaria. Abordaremos los tópicos señalados, planteando que su entidad interpela prácticas teórico-metodológicas de la Antropología Rural en Argentina.

Palabras clave: antropología rural, teoría antropológica, economía política

\section{Summary}

In this work, we analyze the redefinition of the Rural Anthropology field made during the last years, since the setting of a social-economic and cultural scenario characterized by the rising of new economic actors due to the implementation of different rural work exploitation modes, the juxtaposition of productive formats and marketing strategies the incidence of a national and international financial structure, and, basically, due to the launching of a novel system of agricultural income acquisition. We will address the topics mentioned, stating that their identity calls for theoretical-methodological practices of the Rural Anthropology in Argentina.

Keywords: rural anthropology, anthropological theory, economy policy

* Lic. en Cs. Antropológicas. Doctor de la Universidad de Buenos Aires orientación Antropología. Investigador Categoría I, Universidad de Buenos Aires, Buenos Aires, Argentina. El artículo retoma algunos temas que fueron desarrollados en la introducción del libro "Estudios de Antropología Rural". Alejandro Balazote y Juan Carlos Radovich Editores. Editorial de la Facultad de Filosofía y Letras UBA. 2013. Correo-e: abalazote336@gmail.com

** Lic. en Cs. Antropológicas. Doctor de la Universidad de Buenos Aires orientación Antropología. Facultad de Filosofía y Letras, Universidad de Buenos Aires. Departamento de Ciencias Sociales, Universidad Nacional de Luján. Investigador Adjunto del Consejo Nacional de Investigaciones Científicas y Técnicas (CONICET), Buenos Aires, Argentina. Correo-e: sebavalverde@ yahoo.com.ar; sebastianvalverde@conicet.gov.ar 


\section{A manera de introducción}

Se ha señalado en numerosas ocasiones que la Antropología focalizó la atención -desde sus inicios- en el estudio de sociedades y culturas "exóticas", es decir, aquellas que se hallaban en los "márgenes" de la civilización y de las relaciones capitalistas. La construcción residual del objeto de estudio fue uno de los principales obstáculos epistemológicos que trabaron su desarrollo como ciencia y el ocultamiento de las determinaciones políticas y económicas, una de sus peores prácticas.

Considerar a los pueblos originarios como supuestos "relictos del pasado", y a las poblaciones campesinas como resabios de formas sociales precapitalistas, fue el resultado de la división del trabajo intelectual configurado en las ciencias sociales entre fines del siglo XVIII y principios del XX que "asignó" a la Antropología su estudio. En la antropología decimonónica y de la primera mitad del pasado siglo, desde distintas perspectivas teórico-metodológicas, indígenas y campesinos, -en la medida en que eran depositarios de un arcaísmo primitivo y folklórico respectivamente- constituyeron una temática relevante para la investigación.

Quedaba claro que si la Sociología se abocaría al estudio de las nuevas formaciones capitalistas industriales urbanas, la Antropología se concentraría de suyo en ámbitos rurales, "primitivos y arcaicos". Es por esto que cuando la Sociología se plantea "incursionar" en las temáticas vinculadas al campo, ya bien entrado el siglo XX, debe inmediatamente denominarse "Sociología Rural" y de la misma forma, cuando la Antropología comienza a investigar en la ciudad (hecho que se relaciona con el estudio de las migraciones) se especifica que corres- ponde a la "Antropología Urbana". Las limitaciones de esta división que signó los inicios de ambas ciencias son muy evidentes y han sido profusamente analizados. Nos interesa aquí solo señalar que la Antropología Rural como un campo específico de la Antropología Social se constituye retomando ciertos ejes que resultaron constitutivos de la Antropología como disciplina científica.

Por otra parte, resulta evidente la vinculación entre los formatos productivos generales y la producción de conocimiento. En América Latina, la implementación de modelos extractivos agroexportadores implicó la construcción de proyectos políticos y económicos en los cuales las clases dirigentes (preponderantemente las oligarquías terratenientes) controlaron los principales recursos y diseñaron un Estado orientado a disciplinar a los sectores populares en general, y en particular a los campesinos, a los trabajadores rurales y a las poblaciones indígenas. En nuestra región se configuraron complejos escenarios fruto de disímiles procesos históricos, pero que reconocen una matriz común cuya resultante es el ordenamiento de dos modelos contradictorios de territorialización: uno basado en la expansión de las formas capitalistas (que se presenta como hegemónico a partir del accionar de poderosos agentes económicos y políticos) y otro que es fruto de la resistencia de los pequeños productores y de los pueblos originarios en procura de defender su espacio vital. En el marco de esta tensión se fue desarrollando la Antropología Rural. 


\section{La complejidad regional}

América Latina está constituida históricamente por sociedades que basan mayoritariamente su economía en el sector primario. En ciertos países la producción agropecuaria, la recolección y la pesca llevada a cabo por poblaciones originarias y campesinas es sumamente significativa y entra en tensión con un extractivismo depredador ejercido por sectores económicos altamente concentrados. En este escenario, los conflictos entre distintos actores sociales y económicos por la apropiación de la tierra han sido recurrentes. Las fases de surgimiento y consolidación de los Estados Nacionales en América Latina, fueron constitutivas de la estructuración resultante de la distribución y apropiación de los recursos existentes. Parafraseando a Gramsci, "(...) La unidad histórica de las clases dirigentes se produce en el Estado y la historia de esas clases es la historia de los Estados y de los grupos de Estados" (2005: 491). Esta unidad es muy compleja; en el caso latinoamericano se impuso una particular forma de relacionarse con sectores sociales subalternos en general y con las poblaciones campesinas e indígenas en particular, cuyo objetivo central fue el disciplinamiento y la enajenación de los recursos.

La Antropología Rural ha abordado profusamente la problemática de los campesinos y pequeños productores. Sin embargo, el análisis de las configuraciones económicas agrarias recientes a partir de la producción de commodities, es un campo que presenta ciertas áreas de vacancia.

Sin duda el análisis histórico particular enriquece la comprensión de ciertos hechos, pero en aras de entender procesos sociales de amplio rango, queremos reseñar aquí ciertos fenómenos que, con las especificidades de cada caso, se manifiestan en las variadas modalidades socioeconómicas de nuestra región.

Concretamente creemos que el desarrollo de los agronegocios se presenta transversalmente en los países de la región y que el accionar de multinacionales que comercializan nuevas tecnologías sin dudas acontece al interior de una matriz común de relacionamiento con los distintos estados nacionales.

La importancia de abordar estas temáticas reside en que la conflictividad agraria -siempre renovada, siempre redefinida y reconfigurada- suele ser frecuentemente pensada como el correlato de la distribución desigual de los recursos (en particular la tierra), obliterando el análisis de nuevos formatos económicos, nuevas expresiones del relacionamiento de clases y particularmente el rediseño de las relaciones de intercambio.

$\mathrm{Si}$ bien la exclusión social, la dominación política y la transferencia estructural de excedentes son características marcadamente homogéneas de la población rural de nuestro continente, en los últimos años se han pergeñado distintas modalidades y se han consolidado nuevos patrones de acumulación.

El nivel de enfrentamiento y las características del conflicto, se vinculan con las valorizaciones específicas de los distintos recursos en disputa. Tierra y territorio han sido y son concebidos por indígenas y campesinos como medios de vida y/o recursos económicos y consecuentemente han estructurado dinámicas y prácticas sociales de resistencia.

En los últimos años, se ha desarrollado un colosal crecimiento agrícola en los países del cono sur, aumentando el área sembrada y fundamentalmente los rendimientos. El cambio tecnológico producido por la incorporación 
de la biotecnología (semillas transgénicas) y los métodos de labranza (siembra directa) ${ }^{1}$ acrecentó las cosechas exponencialmente, y la presión por el control de los recursos puede constatarse observando el corrimiento de la frontera agraria (Grain, 2014; Mercatante, 2010; Strada y Vila, 2015).

Este proceso implicó mayores requisitos de capitalización, una profunda modificación de las formas de relacionamiento entre el capital y el trabajo y, fundamentalmente, la disociación de la dirección del proceso productivo con la propiedad de la tierra.

A su vez, el proceso de sojización de la economía en Paraguay, Uruguay, Brasil y Argentina $^{2}$, ha disparado la conformación de formatos económicos específicos. En estos países, y en especial éste último al cual pertenecemos, se ha pergeñado así una estructura empresarial que integra redes económico-financieras-productivas de diversas características. A partir de un novedoso sistema de contratos, los "pools" de siembra encaran la actividad arrendando predios y tercerizando la mayor parte de las actividades (siembra, cosecha, acopio y venta) (Gras, 2009). En una entrevista de hace algunos años, y sintetizando el nuevo diseño de la actividad agraria, Gustavo Grobocopatel, uno de los más importantes empresarios argentinos dedicados a la producción de soja, declaraba provocativamente: "Yo podría prescindir de tener tierra, mi negocio no se altera (...) Soy un sin tierra y tampoco trabajo (sino que) contrato servicios de terceros" (Valente, 2008:19).

Figuras paradigmáticas del agro regional como el colono o el chacarero se diluyen y adquieren centralidad los impersonales pooles de siembra ${ }^{3}$, "(...) que extraen enormes riquezas de las zonas en las cuales operan, sin aprovi- sionarse allí de los recursos que necesitan para producir (mano de obra, insumos, etc.)" (Gras y Bidaseca, 2010:12).

De esta manera vemos, cómo la complejidad del nuevo escenario rural hace que debamos replantear nuestras estrategias de investigación. A partir de las configuraciones acaecidas durante las dos últimas décadas, el espacio rural adquiere nuevos sentidos. Su polisemia se conforma, como ya señalamos, a partir de la diversificación de actividades productivas y de comercialización, de la incorporación de nuevas tecnologías, de la emergencia de nuevos actores sociales, de la configuración de nuevos instrumentos financieros y de la resignificación y refuncionalización de antiguas prácticas. Como resultante de esta dinámica el espacio rural se constituye como un campo de disputa política, económica y simbólica (Balazote y Piccinini, 2010).

Quizás uno de los aspectos más significativos de este nuevo escenario es la emergencia, impensada hasta hace pocos años, de distintos conflictos entre actores económicos muy poderosos.

Actualmente asistimos en los países de la región a un fuerte enfrentamiento entre los productores sojeros altamente capitalizados -que no dudan en articular novedosos formatos de acumulación- y otros actores sumamente poderosos: las empresas que los abastecen con semillas de soja modificadas genéticamente. El conflicto se plantea en torno al reconocimiento de la propiedad intelectual. El panorama es disímil, ya que mientras en Uruguay casi la totalidad de los productores reconocen la propiedad intelectual del germoplasma, en Argentina lo hace menos del $40 \%$, mientras que Brasil, Bolivia y Paraguay se encuentran en valores intermedios. 
La comercialización de lo que se denomina "bolsa blanca" que no es más que semillas separadas de la producción originada con "semilla fiscalizada" (y que por lo tanto había pagado las regalías por propiedad intelectual) es sumamente común y constituye una práctica que evita el pago de las regalías.

Cada país tiene su legislación específica respecto al uso de semillas, pero sin duda la diferencia entre el costo de la "bolsa blanca" y aquellas provistas suministradas por las empresas multinacionales que proveen semillas modificadas genéticamente (Monsanto, Nidera, Don Mario, Syngenta; etc.) es muy grande, al punto que desde Argentina se irradia este producto a los países limítrofes vía contrabando.

Las presiones de las semilleras son muy fuertes para que los Estados implementen controles que garanticen el cobro de regalías aunque esto contradiga la legislación vigente (como es el caso de la Argentina). Por otra parte, importantes asociaciones agrarias con un gran poder económico y una efectiva capacidad de lobby, también presionan al Estado para evitar el pago adicional de regalías. Esto que parece circunscrito a la República Argentina en realidad es un tema que, como veremos, se internacionaliza.

En este país, las patronales agrarias lograron que el gobierno neoliberal de Cambiemos (electo a fines de 2015) mediante un resolución ministerial (Resolución 140/2016) impidiera a las empresas semilleras cobrar regalías al momento de embarcar la producción, una vez que se hubiera verificado que provenía de la llamada "bolsa blanca".

Dicha práctica implicaba en realidad una duplicación de los controles, dado que yuxtaponía el control privado con el control estatal.
El significado político de esta determinación nos hace dimensionar el poder del complejo agroexportador al punto que el gobierno argentino (sin duda "market friendly") optó por enfrentar los poderosos intereses de las multinacionales productoras de semillas genéticamente modificadas, consolidando su alianza política con las corporaciones sojeras.

Por su parte, las multinacionales comenzaron una estrategia tendiente a cobrar las regalías por el uso de sus semillas modificadas en los puertos de destino ante la imposibilidad de cobrarlos en los de origen. Esta práctica globalizada muestra que el juego de intereses involucrados (en disputa) en la comercialización de commodities excede los límites nacionales. También nos advierte sobre los riesgos teórico-metodológicos de concebir bloques unificados de distintas facciones de capital, antes bien, lo que muestra es la diversidad de prácticas, estrategias y lógicas que pergeñan diversos sectores que compiten en busca de la obtención de ganancias extraordinarias (Balazote y Piccinini, 2010).

Distintos grupos económicos inscriptos en ciertas actividades extractivas compiten por la apropiación de rentas extraordinarias. La puja no se limita a la "ocupación de espacios productivos" y al control de cadenas de comercialización, sino que remite fundamentalmente a gestionar un relacionamiento particular con los Estados en procura de obtener políticas macroeconómicas favorables a sus intereses.

En este sentido, la determinación de la política cambiaria, monetaria, impositiva y la definición de protocolos de gestión medioambiental se torna central para definir un patrón de acumulación de capital que sin duda resulta más beneficioso para ciertos grupos económicos en detrimento de otros. 
La ampliación del campo de estudio de la Antropología Rural

Como vemos, la Antropología Rural se amplía y se redefine exponiendo claramente los límites de pensarla desde una concepción polar rural-urbano. La yuxtaposición de campos, incumbencias y especificidades nos recuerda el dilema planteado entre el mapa y el territorio. El relevamiento de las realidades locales registradas mediante un abordaje preponderantemente cualitativo constituye un paso ineludible pero que es necesario poner en función de lograr explicaciones de los procesos sociales e históricos de amplio rango. En este sentido rescatamos el valor y la minuciosidad de la experiencia etnográfica, enfatizando su importancia para esclarecer las relaciones sociales de dominación y explotación.

Queda clara la necesidad de pensar los temas a los que tradicionalmente se ha abocado la Antropología Rural desde perspectivas más amplias, que no focalicen exclusivamente en determinados actores sociales sino que aborden el análisis de procesos históricos que incluyen a otros agentes económicos y nuevas modalidades de acumulación.

En línea con lo señalado precedentemente, planteamos a continuación tres temas que consideramos relevantes. Su elección, que sin duda deja fuera de tratamiento importantes tópicos, se debe a que ilustran la complejidad de los nuevos escenarios dispuestos en el ámbito rural, evidenciando la necesidad de reformular los lineamientos teórico-metodológicos de la Antropología Rural contemporánea.

a.- La cuestión ambiental y el riesgo de la utilización de nuevas tecnologías.

b.- La competencia entre alimentos y la producción de energía. c.- Las tensiones por la definición de las políticas macroeconómicas. La carga impositiva y la política cambiaria.

\section{a.- La cuestión ambiental y el riesgo de la utilización de nuevas tecnologías}

Hemos mencionado más arriba el proceso de sojizacion de las economías de Argentina, Brasil, Paraguay y Uruguay (Balazote y Piccinini, 2010; Gras, 2009; Strada y Vila, 2015).

En el año 1996 Argentina aprobó el cultivo comercial de la soja RR, en tanto en Uruguay se autorizó el uso de dicha variedad en el año 1998. En Brasil, por su parte, en marzo de 2005 entró en vigor la Ley de Bioseguridad que permitió el uso de organismos transgénicos, sin la necesidad de contar con estudios de impacto ambiental. A su vez, en el año 2004 el Ministerio de Agricultura de Paraguay aprobó el uso de semillas de soja transgénica y en octubre de 2012, la utilización de distintas variedades de semillas transgénicas de maíz.

El cambio tecnológico producido por la incorporación de la biotecnología (semillas transgénicas) y los métodos de labranza (siembra directa) acrecentó las cosechas exponencialmente y la presión por el control de los recursos se constata observando el corrimiento de la frontera agraria.

La defensa de la siembra directa es generalizada por parte de los numerosos actores económicos que intervienen en el complejo agroexportador y aún desde las estructuras estatales que son altamente dependientes de los ingresos que esta práctica genera. Aun las cuestiones medioambientales que constituyen un aspecto central en los cuestionamientos a dicha modalidad productiva son tratadas de 
manera sesgada y militante. Sobre una multiplicidad de variables e indicadores que constelan la dimensión ambiental, solo reparan en las "ventajas" de la siembra directa por sobre el laboreo mecánico en términos de "conservación de suelos" y "eficiencia hídrica".

No se repara en que el modelo trae "... aparejada una serie de consecuencias en la biodiversidad, en los ecosistemas naturales y en las especies vegetales y animales que son parte de ellos, todos esenciales para sustentar la vida humana y su calidad" (Teubal, 78-79: 2006).

El carácter revolucionario y transformador de la siembra directa y la configuración de un nuevo paradigma productivo son exaltados. Nada se dice de los costos ambientales que tiene el nuevo modelo ${ }^{4}$, ni de las consecuencias sociales que conlleva.

La construcción discursiva en favor de esta modalidad productiva siempre hace referencia a "los productores" sin distinguir las diferentes capacidades productivas, las disímiles relaciones económicas y sociales que mantienen, las desiguales potencialidades de acumulación y la ubicación específica en la cadena productiva y de comercialización. En definitiva se incluye en una misma categoría tanto a un pequeño productor minifundista como a un pool de siembra. Homogeneizar lo heterogéneo es una manera de invisibilizar las dificultades y limitaciones de un sector y los beneficios y superganancias de otro. Esta construcción no diferencia a propietarios de arrendatarios, ni a aquellos agentes económicos que demandan fuerza de trabajo, de quienes la ofrecen: los trabajadores.

En el nuevo esquema productivo, "los proveedores" adquieren gran relevancia en el proceso al punto de constituirse en actores principales, cuya participación es imprescindible para realizar los cambios técnicos, productivos y económicos que requiere el nuevo modelo de acumulación. Son ellos quienes llevan el peso de la constelación de sentidos que estimula, justifica e impulsa las nuevas modalidades productivas.

La innovación es una característica fundamental de la siembra directa. El "desarrollo" nacional (con toda la polisemia del término), llega a partir de la incorporación de las nuevas tecnologías. La siembra directa es una de las vías de acceso a la modernidad y a la eficiencia de un mundo globalizado. En la construcción de esta narrativa ocupa un lugar privilegiado la exaltación del "orgullo nacional", no por casualidad vinculado a lo "campestre".

Considerando que en ciertos países más del $90 \%$ de la producción sojera tiene destino en el exterior, es notable la dependencia de todo el sistema productivo -vinculado a los agronegocios- de la cotización de estos commodities en los mercados internacionales. Las fluctuaciones de los valores negociados en la Bolsa de Chicago inciden marcadamente en las estrategias de los agentes económicos involucrados en la cadena de producción y comercialización.

En ocasiones, algunos entusiastas defensores de las nuevas modalidades productivas -en particular las relacionadas con la producción de soja-se han referido al cultivo como el "maná que cae del cielo" sin brindar precisión acerca de cuáles serían los mecanismos de distribución de ese "maná" y cómo llegaría el beneficio económico a todos. La concepción del derrame de la riqueza ha sido refutada ampliamente y la historia reciente de la región nos muestra que la concentración económica no se revierte sin una 
acción rápida y efectiva por parte del Estado. Por otro lado, la referencia bíblica hace alusión a dones que "caen del cielo", a una existencia en la cual sin esfuerzo se obtiene lo necesario para vivir, el trabajo está invisibilizado y la distribución no requiere ninguna intervención en particular, dado que simplemente la "caída del maná" garantizaría el "beneficio de todos". No por casualidad, la creación de riqueza, su distribución y la reproducción de la desigualdad no tienen cabida dentro de esta figura.

\section{b.- Nuevos negocios. La competencia entre alimentos y la producción de energía}

Argentina, Brasil, Paraguay y Uruguay producen centenares de millones de toneladas de granos que poseen un gran potencial bioenergético. Solo Argentina y Brasil generan 158 millones de toneladas de soja de los 324 del total mundial. A su vez producen 116 millones de toneladas de maíz de los 1011 del estimado mundial para 2016 (Informe USDA, 2016).

La posibilidad de destinar una parte de estos granos a la producción de biocombustibles es una alternativa económica permanente que se resuelve en base a la ecuación de los costos de la producción granaria con respecto al precio internacional de los combustibles.

Los "cultivos energéticos" compiten con los destinados a la alimentación provocando la escasez de alimentos y el encarecimiento del precio de los mismos. La utilización de maíz o de soja para producir biocombustibles implica que una parte de la cosecha no se destina a la producción de alimentos. Si el costo de oportunidad de esta opción es alto, genera el incremento del precio de los alimentos afectando regresivamente la distribución del ingreso.
La correlación entre el precio del petróleo y el de los alimentos resulta evidente, y la "justificación" que se le da a destinar parte de la cosecha de maíz y soja para elaborar biocombustibles, enfatiza la conveniencia del uso biocombustibles reparando en razones ambientales. La sustentabilidad de esta práctica constituye un "argumento fuerte" que encubre la intención de obtener superganancias por parte de los agentes económicos involucrados. De igual manera se procede al ponderar la "eficiencia" de la transformación de granos en biocombustibles.

$\mathrm{Si}$ se considera a ambos productos como commodities, el argumento resulta inobjetable. El costo de oportunidad define qué se produce: en este caso el precio del barril de petróleo vuelca a la producción de biocombustibles millones de toneladas de cereales y oleaginosas. Con lógica similar, en algún momento se pontificó en Argentina que el mercado debía decidir "si producimos acero o caramelos" con las consecuencias que supimos sufrir durante décadas.

La interrelación entre ambas opciones del destino de la producción de soja y maíz incide visiblemente en el proceso de la formación de precios. Así, queda claro que el aumento del corte en los combustibles con biodiésel y etanol influye directamente en el precio de la soja y el maíz.

Las exitosas experiencias que aumentaron el porcentaje de corte del biodiésel ampliaron las posibilidades de su comercialización y afectaron directamente las balanzas comerciales de ciertos países, en la medida en que permitieron la sustitución de importaciones de hidrocarburos para abastecer el consumo interno y la ampliación del volumen de exportaciones si las ventas de biocombustibles se realizaban en el mercado internacional ${ }^{5}$. 
Los biocombustibles son considerados como una opción más dentro del campo de comercialización de la producción agraria, como una extensión natural en el espacio de los agronegocios, tanto en los mercados locales como en los internacionales. La reacción de otros sectores vinculados a la producción de alimentos fue muy contundente en la medida en que el aumento de los granos, vinculado fuertemente al aumento del precio de los combustibles, disminuía su rentabilidad.

La controversia inicialmente planteada: "alimentos versus energía", fue renominada acertadamente por el Presidente del Centro de Empresas Procesadoras Avícolas de Argentina como "comida versus nafta" (Domenech, 2012). La necesidad de reconfigurar la matriz energética de los países de la región, garantizando la soberanía alimentaria de sus pueblos, surge como un elemento central de la futura agenda regional.

\section{c.- En busca de políticas macroeconómicas "amigables"}

Este punto remite específicamente al relacionamiento de distintos sectores vinculados a la actividad rural con el Estado. La dimensión política aparece aquí en su máxima expresión. No procuramos en esta ocasión plantear solamente que "el agro" se relaciona con los poderes estatales bajo determinados formatos sino que -lejos de constituir un homogéneo núcleo de actores económicos y sociales- cada sector puja por obtener la sanción de medidas gubernamentales propicias que pueden resultar altamente contradictorias con las que solicitan otros agentes agrarios.

Sin embargo, tres temas de la "agenda rural" sobresalen del cúmulo de reclamos sectoriales que conforman un claro revival del laissez-faire, laissez-passer fisiocrático: la política cambiaria, la carga impositiva y finalmente las leyes y normativas que regulan el acceso a los recursos naturales (Mercatante, 2010; GRAIN, 2004; Forlani, 2012).

En relación al primer tópico, es un clásico plantear el "atraso cambiario". Dicho de otra manera, el reclamo apunta a la devaluación de las monedas locales que, como es sabido, no es más que una reconfiguración de los precios relativos. En tal reconfiguración los sectores populares ven recortados drásticamente sus salarios implementándose una transferencia estructural de recursos.

El impacto de la devaluación sobre los salarios solicitada por los agentes económicos vinculados al complejo agroexportador, no solo se da por el encarecimiento de los insumos necesarios para producir y de los bienes de consumo importados que adquieren los trabajadores, sino que los mercados locales deben pagar por los alimentos exportados a los precios que define el mercado internacional.

Queda claro que el impacto de las variables macroeconómicas en los restantes sectores productivos y agentes económicos no es considerado y solo se expone un reclamo sectorial de agentes sociales que han mostrado una larga tradición de victimización. Se omite que los ciclos "...de precios internacionales relativamente elevados para las materias primas y los alimentos, empujan hacia arriba los precios internos de los transables, mientras que la tasa de devaluación los multiplica" (Kicillof, 2010).

Otro punto que concentra fuertes reclamos sectoriales es la presión tributaria ejercida por los Estados. La proyección de un productor expoliado por la voracidad estatal es una figura constante en la estructuración discursiva del sector. Se construye una narrativa que presenta 
a un productor (nunca se menciona a la totalidad de agentes económicos intervinientes en el complejo agroexportador) que sufre una fuerte quita (o expropiación) de lo que produce.

Los agentes económicos que intervienen en el complejo agroexportador establecen una marcada sintonía con importantes grupos mediáticos que "producen sentido" y generan "consenso" sobre la justicia de sus reclamos, realizando permanentes acciones de lobby ante distintos grupos políticos para obtener condiciones macroeconómicas más favorables ${ }^{6}$.

La amenaza de discontinuar la producción dada la "pérdida de rentabilidad" es recurrente, pero rara vez se cumple, siendo mucho más común la reorientación de su práctica empresaria hacia otras actividades que permiten mayores niveles de acumulación.

En relación a la supuestamente excesiva presión tributaria que sufrirían, se recurre a una explicación monocausal: las dimensiones exorbitantes del Estado que originan un creciente déficit fiscal que debe ser cubierto con el aumento de los impuestos que paga el sector. Una pléyade de economistas y tributaristas financiados por los grupos agroexportadores aportan insumos técnicos y argumentos de política económica. Sus líneas discursivas replican el "abc del neoliberalismo" según cuya concepción toda carga impositiva quita estímulos a los "emprendedores" para aumentar la producción, innovar o invertir en nuevos negocios que "crearían más fuentes de trabajo" y "aumentarían la recaudación".

Recitando argumentos del mainstream económico, los planteos se centran en la confiscatoriedad y superposición de tributos múltiples (doble imposición) sobre un producto. Así, se confunden gravámenes de muy distinto tipo, que no necesariamente afectan a los mismos actores sociales: el impuesto a los bienes personales, impuestos inmobiliarios, impuestos a la herencia y a las donaciones se yuxtaponen e involucran en una misma narrativa de queja que victimiza a los agentes "del campo" y se resume en un "enunciado de consigna": la confiscatoria presión tributaria que soportan los productores ${ }^{7}$ por parte del Estado.

Cuando los gobiernos plantean medidas que afectan las superganancias del sector en procura de implementar mecanismos redistributivos, se configura un escenario controversial que adquiere tal nivel de violencia que es capaz de amenazar el funcionamiento institucional y el abastecimiento alimenticio.

Se plantea una línea argumental que procura instalar la dependencia absoluta de los países de la región con respecto al sector agrario local. Tal explicación, contiene una violencia discursiva extrema aplicada a la implementación de proyectos económicos de exclusión. La articulación de una narrativa antiindustrialista y la afirmación de que los países son fuertemente agrodependientes tiene por objetivo estratégico imponer condiciones macroeconómicas favorables.

El sector del agro (en realidad, los agentes económicos vinculados al complejo agroexportador) se representan a sí mismos como "el motor del progreso" que solo subsiste por su empuje y laboriosidad mientras que los demás sectores sociales constituyen un cuerpo social, económico y productivo amorfo y parasitario, carente de un proyecto económico propio. En dicha construcción se configuraría ficcionalmente un país sin explotados, sin clases y sin trabajadores que diseña un patrón de acumulación que le arranca los frutos de la tierra "al campo". Esta visión oblicuamente fisiocrática confiere al agro la cualidad de ser el único 
ámbito de creación de valor. Valor que es enajenado por otros sectores sociales a través de la implementación de políticas macroeconómicas.

De esta manera, "el campo" tiene un tipo particular de relacionamiento con los gobiernos, en ocasiones construidos como un enemigo y otras veces como un aliado, y con el Estado, pensado como un ámbito de disputa de clase. Los buenos gobiernos son, de acuerdo a su caracterización, aquellos "que no gobiernan", que no interfieren en sus negocios y no ponen límites a su acumulación.

\section{¿Y los campesinos y los pequeños productores?}

Después de abordar estos temas, que no integran el "núcleo duro" tradicional del campo antropológico, veamos someramente su relación con agentes económicos que la antropología ha abordado profusamente. Nos referimos a los pequeños productores y a los campesinos cuya producción resulta fundamental para el abastecimiento de la población. Como es sabido, su producción está mucho más ligada al consumo interno que a la exportación de alimentos.

Deseamos efectuar en este punto, una serie de aclaraciones. En Argentina, de acuerdo al análisis efectuado por Scheinkerman de Obschatko et al. (2007) en base a datos del Censo Nacional Agropecuario del año 2002, se considera pequeños productores a 218.868 explotaciones agropecuarias sobre un total de 333.477 (es decir un 65,6\%). El nivel de concentración de la tierra en nuestro país, se evidencia al observar que este segmento de pequeños productores posee tan solo el $13,5 \%$ del área total de la superficie de la tierra cultivada, en tanto las explotaciones mayores, que corresponden en cantidad al $34,4 \%$ del total, cuentan con el $86,5 \%$ de la tierra de nuestro país.

Este segmento de pequeños productores constituye el eslabón más débil del circuito que va de la producción al consumo final. Es sobre él que se concentran los "ajustes" de la cadena de valor. Resulta un clásico de las innumerables notas periodísticas que reflejan la crisis del sector, plantear escandalizados, la comparación entre los dos extremos; es decir, el precio que se le paga (sin especificar nunca quién) al productor y el precio que se le cobra (nuevamente sin brindar mayores precisiones) al consumidor. Utilizando el inespecífico término de "la intermediación", se soslaya el análisis del accionar de los formadores de precios y el rol que juega cada actor en el proceso que media entre el momento de subir la producción al camión que la transporta, hasta la remarcación en la góndola.

Bajo el eufemismo del "mercado", concebido como un espacio social y económicamente neutro, se intenta explicar desde determinados agentes sociales y medios de comunicación la regresiva distribución del valor generado en la producción. Nos interesa señalar que los pequeños productores no son capitalistas, pero producen mercancías y sus productos se comercializan bajo el efecto de la violencia que el capital ejerce en dicho ámbito.

Su producción no se basa fundamentalmente en el trabajo asalariado (aunque esto no significa que en ocasiones incorporen mano de obra asalariada durante el período de cosecha, esquila, etc.) sino que se sustenta esencialmente en el trabajo familiar. Es en ese ámbito en donde se produce la subsunción indirecta del trabajo familiar al capital (Balazote, 1999). 
Su lógica es muy distinta a la desarrollada por las empresas capitalistas y su reacción ante las fluctuaciones del mercado diametralmente opuestas (Chayanov, 1981). La autoexplotación y la flexibilidad organizativa frente a la reducción de los ingresos caracteriza estas formas productivas. Una empresa capitalista puede reducir el número de empleados frente a la merma de la rentabilidad, pero una familia no puede "deshacerse" de ninguno de sus miembros por más que los precios de lo producido bajen.

La crisis del sector no es un hecho aislado, ni es el efecto "no deseado" y transitorio de las políticas económicas implementadas. Los pequeños productores han sido impactados por planes de gobierno, que en realidad son planes de negocios, cuya centralidad pasa por la valorización financiera y la transferencia de recursos a los sectores agroexportadores y a las corporaciones económicas que desarrollan prácticas extractivas.

La ausencia de apoyo oficial y la implementación de políticas macroeconómicas neoliberales impactan negativamente sobre campesinos y pequeños productores poniendo en serio riesgo su reproducción social. La apertura indiscriminada de las importaciones, el retraso del tipo de cambio, el precio de los combustibles y servicios, afecta no solo las condiciones de comercialización sino la estructura de costos, lo que hace disminuir notablemente sus ingresos. Tal es el caso de los productores frutihortícolas del Alto Valle de las provincias de Río Negro y Neuquén que en Agosto de este año (2016), efectuaron una particular protesta en pleno centro de la ciudad de Buenos Aires, regalando 10.000 kilos de manzanas y peras, con el fin de hacer visible la crisis del sector ${ }^{8}$.

Es sabido que el control de los elementos necesarios para la producción, la incorporación parcial de trabajadores y el involucramiento del trabajo familiar conforma una estructura que selectivamente permite alcanzar (en ocasiones) ciertos niveles de acumulación.

La dinámica resultante de la transferencia estructural de valor contrapuesta con procesos puntuales y acotados de acumulación de ciertas unidades productivas, nos lleva a la interesante pregunta acerca de cuál es -a futuro- la suerte de estas formas productivas y en base a qué condiciones locales, regionales, nacionales y supranacionales se definen sus posibilidades de desarrollo. En la misma línea nos interrogamos acerca en qué medida la percepción del control de la producción y la comercialización no es más que un relato ficcional que apunta a preservar ciertos formatos productivos viables en etapas de un proceso de concentración económica.

\section{Consideraciones finales}

Hemos planteado, sin ninguna pretensión de exhaustividad, algunas consideraciones sobre el escenario disciplinar de la Antropología Rural en Argentina, en el particular contexto actual.

La sucinta exposición de ciertos temas fue realizada con la intención de exponer la compleja dinámica del espacio rural a la luz de los cambios socioeconómicos recientes. 
Las prácticas económicas y políticas de los distintos actores sociales conforman un amplio y complejo campo de disputa cuyo abordaje nos exige implementar nuevas prácticas de investigación. El tránsito entre las realidades locales y los procesos globales requiere explicaciones que superen el mero nivel enunciativo.

Los aspectos simbólicos no están disociados de la lucha económica y política y las construcciones narrativas elaboradas por los distintos actores sociales adquieren tanta materialidad como sus prácticas productivas, sus estrategias de comercialización y los nuevos formatos económicos que se han desarrollado en las últimas décadas en el espacio rural.

Los conflictos ocasionados por la apropiación de ganancias extraordinarias y la distribución de la renta agraria, exceden la clásica dimensión de la "lucha política". La disputa de sentidos adquiere una relevancia central para comprender la lógica sectorial y las prácticas específicas de los distintos actores que pujan por presentar sus intereses particulares como beneficiosos para el conjunto de la sociedad.

Frente a este dinámico escenario surge la necesidad de redefinir las prácticas y tradi- ciones de la Antropología Rural. Las respuestas que debe brindar este campo específico de la Antropología ante tal panorama disciplinar, no son solo teóricas sino también metodológicas y epistemológicas. No se trata de justificar neciamente su necesidad y validar su existencia, sino de reformularla y constituirla en un instrumento central para el análisis de nuevas realidades.

Entendemos que el contexto actual nos plantea con especial énfasis la necesidad de profundizar diversas cuestiones que involucran a este campo disciplinar. Una de ellas es la relación entre lo rural y lo urbano, distanciándonos de las lecturas que la conciben en términos dicotómicos, y no en forma articulada y en permanente redefinición. El otro aspecto, remite a las políticas actuales y la forma en que afectan a los pequeños productores rurales (de lo cual el "frutazo" que mencionamos es un claro ejemplo). Por último, deseamos enfatizar la complejidad del mundo social -del cual los diferentes actores del ámbito rural desde ya no están exentos-. Un claro ejemplo de ello lo constituyen las disputas entre sectores empresariales que vimos a lo largo de este trabajo. 


\section{Notas}

${ }^{1}$ La denominada "siembra directa" es una técnica de cultivo que no requiere la roturación del suelo. La labranza sin arado incrementa la cantidad de agua que se infiltra en la superficie, aumenta la retención de materia orgánica y la conservación de nutrientes. Permite producir sin degradar el suelo, aumentando la eficiencia hídrica.

${ }^{2}$ Al observar la evolución de las cosechas de los años 1996/97 en relación a las de 2013/2014, se evidencia la magnitud de este proceso de sojización en Argentina. En efecto, los datos revelan un exponencial crecimiento de la superficie cultivada de soja, pasando en este período de 6,7 millones de hectáreas a 19,8 millones. Como contrapartida, el trigo se redujo entre ambos registros, de 7,3 millones de hectáreas cultivadas a 3,6 y el girasol de 3,1 a 1,3 millones (Strada y Vila, 2015). A ello deben sumarse los efectos socioambientales, con el desplazamiento de otras producciones, la deforestación, el declive y pérdida de empleos, la destrucción de unidades de producción familiar, la precarización laboral, el crecimiento del trabajo transitorio, bajos salarios; etc.

${ }^{3}$ Pool de siembra es la denominación que recibe en la Argentina un sistema de producción agraria caracterizado por el papel determinante jugado por el capital financiero y la organización de un sistema empresarial transitorio que asume el control de la producción agropecuaria, mediante el arrendamiento de grandes extensiones de tierra y la contratación de equipos de siembra, fumigación, cosecha y transporte, con el fin de generar economías de escala y altos rendimientos para todos los participantes. Al finalizar la cosecha y realizarse el producto, las ganancias son distribuidas.

${ }^{4}$ Para ampliar este tema ver el trabajo de Paganelli et al. (2010).

${ }^{5}$ En Argentina las restricciones implementadas en el año 2011 por China para la compra de aceites de soja fueron absorbidas convirtiendo el aceite en biodiesel y volcadas al mercado local incrementando el corte del 5 al $7 \%$.

${ }^{6}$ Ver el artículo que publicamos en otra oportunidad, (2012). Los suplementos "del campo". Instrumentos estratégicos en la disputa de la renta agraria (Balazote, 2012) En: Realidad Económica. № 270. Pp. 58-74. Instituto Argentino para el Desarrollo Económico.

${ }^{7}$ Esta afirmación no es neutra dado que homogeneiza a agentes económicos de diferente matriz productiva, que desarrollan procesos productivos en base a disímiles relaciones de producción, que se insertan de distinta manera en la estructura de comercialización y fundamentalmente que cuentan con desiguales capacidades de acumulación de capital.

${ }^{8}$ Ver el artículo "Las políticas económicas que derivaron en el frutazo"que publicamos los autores del presente (Alejandro Balazote y Sebastián Valverde, junto a Liliana Landaburu, Mónica Aurand y Magalí Paz (“Infonews", 02/09/2016). 


\section{Referencias bibliográficas}

Balazote, A. (2012). "Los suplementos 'del campo'. Instrumentos estratégicos en la disputa de la renta agraria". En Realidad Económica. № 270.

(1999). "Relaciones entre capital y trabajo en grupos mapuche de norpatagonia". En: S. Narotzki, J. Tudela y U. Martínez Veiga (Comp.). Antropología y Economía Política. FAAEE.

Balazote, A. \& Piccinini, D. (2010). "Los efectos de la crisis global en la Argentina de la Post Convertibilidad. La racionalidad económica en discusión". En: Política e Sociedade. Revista de Sociología Política. Programa de Posgraduaçao em Sociología Política. V. 9 - № 17.

Balazote, A.; Valverde, S.; Landaburu, L.; Aurand, M. \& Paz, M. (2016). "Las políticas económicas que derivaron en el frutazo" ("INFOnews", 02/09/2016).

http://www.infonews.com/nota/301190/las-politicas-economicasque-derivaron Fecha de consulta: 10 de diciembre de 2016.

Chayanov, A. V. (1981). "Sobre la teoría de los sistemas económicos no capitalistas". En Chayanov y la teoría de la economía campesina. México: Ediciones Pasado y Presente.

Domenech, R. (2012). "Polémica en la granja", Diario Clarín, Suplemento Rural, 18-02-2012. Disponible: https://www.clarin.com/ rural/Polemica-granja_0_SkizlBwnPmg.html Fecha de consulta: 28 de abril de 2017.

Forlani, M. (2012). Tres enfoques teóricos-ideológicos para analizar el lockout del sector agrario al gobierno de Cristina Fernández durante el año 2008. Revista electrónica de Psicología Política Año 9 № 27 - Noviembre/Diciembre de 2011. http://www.psicopol.unsl. edu.ar/abril2012-nota06-Enfoques\%20teoricos-version\%20definitivaREVISADO.pdf Fecha de consulta: 10 de diciembre de 2016.

Godelier, M. (2016). "En el mundo de hoy, la antropología es más importante que nunca". En Revista de Antropología Iberoamericana. №1.

Gramsci, A. (2005). Antología. Selección, Traducción y Notas, Manuel Sacristán. Buenos Aires: Siglo Veintiuno Editores Argentina.

Gras, C. (2009). "El nuevo empresariado agrario: sobre la construcción y los dilemas de sus organizaciones", en Carla Gras y Valeria Hernández (coords.). La Argentina rural: de la agricultura familiar a los agronegocios. Buenos Aires: Editorial Biblos.

Gras C. \& Bidaseca, K. (2010). El mundo chacarero en tiempos de cambio. Herencia, territorio e identidad en los pueblos sojeros.
Buenos Aires: Ediciones CICUS.

GRAIN (2004). "Monsanto y las regalías semilleras en Argentina. O cómo las corporaciones continúan imponiendo sus pretensiones para aumentar sus ganancias con la complicidad de los gobiernos". Disponible en:https://www.grain.org/article/entries/149-monsanto-ylas-regalias-semilleras-en-argentina

Kicillof, A. (2010). Teorema cambiario. "Página 12", 19-12-2010. https://www.pagina12.com.ar/diario/suplementos/cash/43-48502010-12-19.html Fecha de consulta: 10 de diciembre de 2016.

Mercatante, E. (2010). La naturaleza de la renta agraria en Argentina. Los efectos de su apropiación parcial vía retenciones. IPS Blog de debate. http://www.ips.org.ar/wp-content/uploads/2011/04/ Mercatante_Esteban_La_naturaleza_de_la_renta_agraria_en_ la_Argentina._Los_efectos_de_su_apropiaci\%C3\%B3n_parcial_ mediante_retenciones_2002-2008.pdf Fecha de consulta: 10 de diciembre de 2016.

Obschatko, Scheinkerman de, E.; Foti, M. del P. \& Román, M. (2007). Los pequeños productores en la República Argentina: importancia en la producción agropecuaria y en el empleo en base al censo nacional agropecuario 2002. Secretaría Agricultura, Ganadería, Pesca y Alimentos. Dirección de Desarrollo Agropecuario: Instituto Interamericano de Cooperación para la Agricultura- Argentina, 2007.

Paganelli, A.; Gnazzo, V.; Acosta, H.; López, S. \& Carrasco, A. (2010). Glyphosate-Based herbicides produce teratogenic effects on vertebrates by impairing acid signaling. Chemical Research in toxicology, № 23 .

Strada, J. \& Vila, I. A. (2015). "La producción de soja en Argentina: causas e impactos de su expansión". La revista del CCC, №23. Disponible: http://www.centrocultural.coop/revista/articulo/550/ la_produccion_de_soja_en_argentina_causas_e_impactos_de_ su_expansion.html

Teubal, M. (2006). "Expansión del modelo sojero en la Argentina. De la producción de alimentos a los commodities", Realidad Económica, № 220.

USDA Informe (2016). "USDA Informe del USDA - Mayo 2016". GRANAR. Disponible en: http://www.granar.com.ar/nota. asp?cid=46849 Fecha de consulta: 28 de abril de 2017.

Valente, M. (2008). "Los dueños del negocio". En: Mundo Contemporáneo, № 10. Buenos Aires. http://www.ts.ucr.ac.cr/ binarios/reconcep/reconc-00281.pdf Fecha de consulta: 10 de diciembre de 2016. 